\title{
Review \\ Freshwater conservation planning in South Africa: Milestones to date and catalysts for implementation
}

\author{
Dirk J Roux ${ }^{1,2,3 *}$ and Jeanne $\mathrm{L} \mathrm{Nel}^{4}$ \\ ${ }^{1}$ Scientific Services, South African National Parks, George, South Africa \\ ${ }^{2}$ Sustainability Research Unit, Nelson Mandela Metropolitan University \\ ${ }^{3}$ Water Research Node, Monash South Africa \\ ${ }^{4}$ Natural Resources and the Environment, CSIR, Stellenbosch, South Africa
}

\begin{abstract}
Since the 1970s, at approximately 10-year intervals, 4 national-scale freshwater conservation plans have been developed for South Africa. These 4 plans reflect different but broadly advancing approaches to conservation planning. We provide an overview of 3 historical plans and a more detailed discussion of the most recent plan which is based on a systematic approach. The main principles of systematic conservation planning, namely, to achieve representation, persistence and efficiency, are introduced. We then describe how these principles were used to develop National Freshwater Ecosystem Priority Areas (FEPAs) for the whole of South Africa. A strong implementation orientation influenced the development of FEPAs. End users were engaged throughout the planning process and map products were designed with user needs as well as relevant policy and legal contexts in mind. We believe that the process that was followed in developing FEPAs marks a new level of implementation-driven planning. Remaining constraints to effective implementation now lie mainly on the side of the receiving environment - i.e. the operating environments of those agencies with mandates to manage and conserve freshwater ecosystems. To this end we highlight 4 potential catalysts for effective implementation in the receiving environment, namely, absorptive capacity, multi-party cooperation, science extension and adaptive management. We conclude by calling for a new and broad research initiative linked to implementing FEPAs.
\end{abstract}

Keywords: absorptive capacity, biodiversity surrogates, cooperation, efficiency, persistence, representation

\section{Introduction}

Freshwater is both an essential and a finite natural resource and constitutes only $2.5 \%$ of the water on Earth. Less than $0.3 \%$ of all freshwater can be found in rivers, lakes and the atmosphere (Shiklomanov, 1993), yet the quality and availability of freshwater affect every aspect of human endeavour. Without the multitude of goods and services derived from freshwater ecosystems, human societies will cease to thrive if not to survive (Daily, 1997). The use of freshwater ecosystems by people and the ability of these systems to provide services are interlinked, prompting the need for wise stewardship; the use and conservation of freshwaters have to be carefully balanced.

A central principle of conservation science is to set aside representative samples of ecosystems to act as biodiversity banks or proactive protection against future modifications. Systematic conservation planning has, over the last 30 years, evolved into a widely accepted framework for identifying and prioritising ecosystems for protection to minimise the loss of biodiversity and ecosystem services (Pressey and Bottrill, 2009). Traditionally, freshwater ecosystems have received poor attention from systematic conservation planning exercises, often relying on incidental inclusion within a protected or conservation area, the design of which has been driven by

\footnotetext{
* To whom all correspondence should be addressed.

용 +27 44871 0109; e-mail: dirkr@sanparks.org

Received 1 March 2012; accepted in revised form 19 November 2012.
}

terrestrial biodiversity features (Abell et al., 2007; Roux et al., 2008b). However, since the early 2000s systematic conservation planning for freshwater ecosystems and species has emerged and grown purposefully to become a new and applied branch of conservation biology (see reviews by Nel et al., 2009; Linke et al., 2011).

To date, South Africa has featured as one of a few growth centres globally for freshwater conservation planning. Thanks to the sustained commitment over the past 8 years of national organisations such as the Water Research Commission, CSIR, South African National Biodiversity Institute and the Departments of Water Affairs and Environmental Affairs, research and implementation efforts have now culminated, through a multi-year cooperative initiative, in the publication of spatially explicit priority areas for conserving rivers, wetlands and estuaries for the whole of South Africa (Nel et al., 2011a). These areas are referred to as Freshwater Ecosystem Priority Areas (FEPAs).

In this paper we reflect on the state of freshwater conservation in South Africa in terms of technical planning advances as well as the institutional mainstreaming of planning outcomes. We limit our discussion to national-scale plans, starting with a brief overview of historical freshwater conservation plans and a more detailed presentation of post-2000 developments. Integral to the most recent approach is a strong focus on the need to implement conservation plans. To this end we highlight a number of challenges and strengths in achieving such implementation, with the aim of providing direction for sustaining the current momentum in implementation-focused freshwater conservation efforts in South Africa. 


\section{Glossary of terms used in conservation planning}

- Biodiversity features refer to those components of biodiversity that are targeted in a conservation planning exercise. Examples of biodiversity features include river ecosystem types and species of special concern, or processes such as hydrological connectivity or seasonal migration corridors.

- Biodiversity surrogates are proxy measures of biodiversity used to represent the full suite of biodiversity, especially in the absence of more detailed information. Because detailed measures of biodiversity (including genetic- and species-level data) are mostly not available for large-scale study areas, landscape-level geographic features are often used as surrogates for general biodiversity. A critical assumption is that abiotic surrogates represent biotic biodiversity features. Landscape- or ecosystem-level surrogates are also referred to as a coarse-filter approach and may be complemented by a fine-filter approach such as data on species of special concern.

- Complementarity ensures that each new planning unit that is selected complements (rather than replicates) the previously selected units in terms of their biodiversity features.

- Efficiency is a planning principle that strives to optimise biodiversity features per planning units -i.e. to get the highest biodiversity returns for the least land acquisition. Efficiency is incorporated through employing the concept of complementarity.

- Gap analysis measures the extent to which targets for representation of biodiversity features have been achieved by existing protected areas.

- Persistence strives to conserve those ecological processes that generate and maintain biodiversity in an area so that biodiversity can persist and naturally evolve over time.

- Planning units are the spatial entities which are assessed in a planning domain. Planning units best suitable to achieving biodiversity targets are then selected. Planning units thus serve as spatial building blocks for designing a conservation plan. In freshwater conservation these units are often sub-catchments or river reaches.

- Representation strives to conserve an adequate sample of the full spectrum of biodiversity in an area.

- Systematic approaches to conservation planning seek to achieve representation of biodiversity through setting biodiversity targets and employing the principle of complementarity. This targetdriven approach is an advance on previous approaches which select important sites for conservation because they are easily obtainable, well studied or perceived by experts to be of high conservation importance (e.g. biodiversity hotspots).

- Targets refer to minimum requirements that have to be achieved to represent the identified biodiversity features in a planning domain. Such targets are expressed in quantitative terms, for example $20 \%$ of the length of each river ecosystem type, or 3 viable populations of each fish species.

\section{History of national-scale conservation plans}

Since the 1970s, at approximately 10 -year intervals, 4 nationalscale freshwater conservation plans have been developed for South Africa. These 4 plans reflect different but broadly advancing approaches to conservation planning. In the 1970s, Noble (1974) evaluated the conservation status of some 40 aquatic biotopes classified according to a mixture of biological and physical attributes. These attributes included dominant vegetation type, geomorphological zonation, river size and flow variability (Fig. 1a). Based on this analysis recommendations were made for the conservation of 25 representative sites, and further identified which of those had no formal protection at the time (Noble, 1974). This study was ahead of its time in many ways. It produced a protected area gap analysis for aquatic biotopes and habitats of threatened species, an approach that would only be formalised in terrestrial conservation planning some 20 years later (Scott et al., 1993), and is still, to a large extent, lagging for freshwater systems (Nel et al., 2009). It also strove for efficiency in the use of conservation resources, attempting to minimise the number of sites selected by aligning freshwater sites where possible with areas that also contained important terrestrial conservation features. Furthermore, this study aimed to integrate the conservation and use of freshwater ecosystems, in that 'the conservation of these sites should not preclude their water resources being utilised in a rational way’
(Noble, 1974 p. 71). However, it differed from more recent approaches to conservation planning in that aquatic biotopes were descriptive rather than spatially explicit and the sites that were recommended for conservation were relatively well known by experts rather than chosen through systematic analysis of the options across the entire landscape.

In the 1980s, 144 river sites of 'outstanding conservation importance' in South Africa were spatially identified (Fig. 1b) based on expert opinion (O’Keeffe, 1986). The map thus produced was intended as a starting point for conservation action, but also recognised that more detailed classification of rivers and river zones would be required to effectively inform management priorities (O’Keeffe et al., 1989). In an attempt to be more quantitative and consistent, this project was followed by the development of an expert-driven 'River Conservation System' to assess the relative conservation importance of different rivers and to communicate the results to decision-makers (O’Keeffe et al., 1987). The River Conservation System was a semi-numerical system in which several biological and physical attributes were weighted and scored based on expert knowledge and informed by quantitative data where available. The system offered flexibility over traditional scoring approaches in that it provided the user with rules that could be applied to change the relative importance of the weightings to different settings (e.g. regional differences in biota, differences related to river size). While the system provides a means of assessing relative 

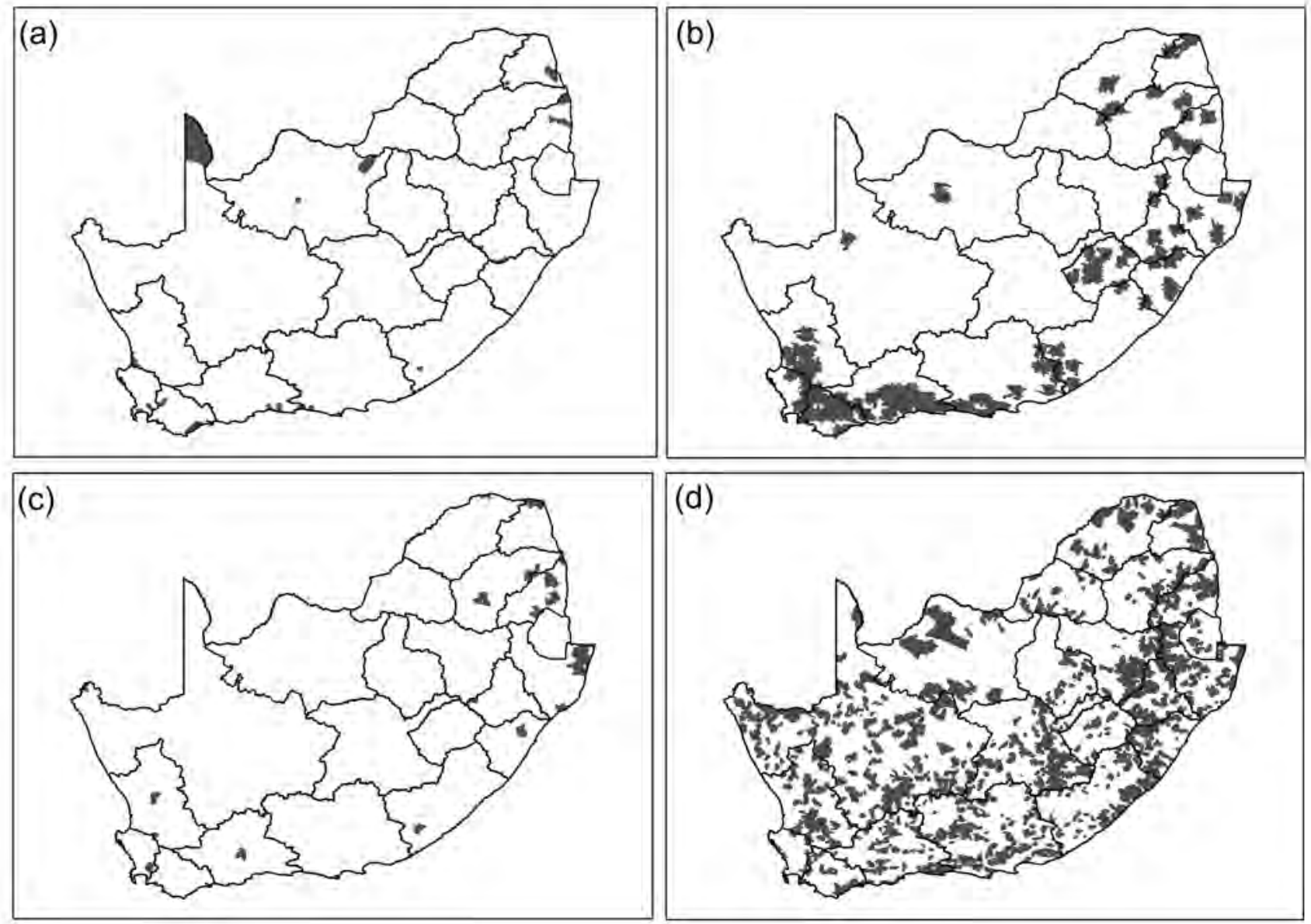

Figure 1

National strategic priority areas for conserving freshwater ecosystems and associated biodiversity by (a) Noble 1974, (b) O'Keeffe (1986), (c) Skelton et al. (1995) and (d) Nel et al. (2011a). Priority areas identified in (a)-(c) were interpreted to the nearest sub-catchment boundaries that were used by Nel et al. (2011a) as part of the identification of Freshwater Ecosystem Priority Areas.

importance of several rivers across a landscape, it seems to have been applied only in assessing the relative importance of 3 to 4 rivers at a time. This was possibly a consequence of a labour-intensive approach and computing limitations at the time.

In the 1990 s, the first national, spatially explicit and systematic conservation plan was developed for freshwater fish species in South Africa (Skelton et al., 1995). An extensive museum database of freshwater fish collections was fed into an iterative reserve selection algorithm to produce a minimum set of sites that would together protect each species at least once. Twenty quarter degree squares (15' x 15') of 'maximum importance' were thus identified (Fig. 1c). Although the adequacy of representing only 1 population of each fish species is questionable, and the planning units used were not as relevant to rivers as catchments would have been, the 20 priority sites thus identified broadly encapsulated the pattern of fish species richness, endemism and threat in the country.

In the 2000s, 4 synergistic national developments helped to set the scene and create broad institutional support for the development of the fourth national conservation plan for freshwater ecosystems. The first of these developments was the publication of the National Water Resource Strategy (DWAF, 2004), which under the National Water Act (Act No. 36 of 1998) called for the protection of the ecological functioning of freshwaters, implemented through a water resource classification system whereby every water resource is classified according to the degree of use/protection awarded to it. The second development was the publication of a number of State-of-River reports (Strydom et al., 2006) using results from the national River Health Programme (see http://www.dwa.gov.za/iwqs/ rhp/index.html). Based on biological response measures (such as indices focusing on fish assemblages, invertebrate communities and riparian vegetation), these reports showed that the ecological integrity of many rivers was severely impaired, raising questions about how many and which rivers should be protected. The third development was the National Spatial Biodiversity Assessment (NSBA) undertaken for South Africa in 2004. The freshwater component of the NSBA focussed on mainstem river ecosystems. Geomorphic provinces (Partridge et al., 2010) and hydrological variability (Hannart and Hughes, 2003) were used to delineate 112 ecosystems associated with main rivers, which were used as coarse-filter surrogates of river biodiversity (Nel et al., 2007). Tributaries were excluded because consistent data on river integrity could only be generated for mainstems. In addition to mainstem rivers, the 2004 NSBA also dealt with terrestrial, estuarine and marine ecosystems. This assessment highlighted the relative and overall poor state of South Africa's river systems (Driver et al., 2005), heightening the awareness in both the conservation and water 
sectors of the urgency for strategic conservation action to protect freshwater biodiversity. This awareness, coupled with the need for coordinated and cooperative action by mandated agencies spanning several government sectors, prompted the fourth development, namely, to formulate a national vision for freshwater conservation which is underpinned by cross-sector policy objectives. The cross-sector engagement process was initiated in 2005 and led to the development of a hierarchical policy framework. This framework links a national goal for conserving freshwater biodiversity, through a set of cross-sector policy objectives and implementation principles, to practical implementation recommendations (Roux et al., 2006; Roux et al., 2008a).

In 2011, the fourth national freshwater conservation plan was completed (Fig. 1d), identifying strategic spatial priority areas for conserving rivers, wetlands and estuaries (Nel et al., 2011a). These areas, known as Freshwater Ecosystem Priority Areas (FEPAs), were identified based on a range of criteria dealing with the maintenance of key ecological processes and the conservation of ecosystem types and species associated with rivers, wetlands and estuaries. A systematic conservation planning approach was used to achieve explicit targets for these criteria in a spatially efficient manner (Nel et al., 2011b). The approach incorporated the expertise of over 100 stakeholders (comprising aquatic ecologists and natural resource use practitioners). Spatial data used to inform the selection of FEPAs were collated and then reviewed in a series of 5 three-day review workshops in different regions of the country. Identified FEPAs were reviewed by aquatic ecologists and managers over a two-day national workshop. FEPA maps (Fig. 2) were compiled for each of South Africa's 19 Water Management Areas, which are the administrative catchment units within which the Department of Water Affairs manages water resources.

This most recent systematic conservation planning exercise resulted in the most comprehensive freshwater conservation plan for South Africa to date, identifying FEPAs comprising 22\% of South Africa's river length, 38\% of wetland area and $41 \%$ of estuaries (Nel at al., 2011b). The planning approach also coupled the technical component of identifying FEPAs to an implementation component. The implementation component focused on promoting an implementation-enabling environment at national and sub-national levels. At a national level, alignment of water and conservation policy mechanisms and tools was sought. At a sub-national level, 3 case study areas were used to test how FEPAs could be applied to influence planning and decisionmaking processes for land and water resources; for example, testing the potential for incorporating FEPAs into a catchment management strategy or a provincial land use planning exercise. This implementation component resulted in the production of an implementation manual that provides guidance on how to effect the implementation of FEPAs in different policy contexts (Driver et al., 2011)

\section{Systematic conservation planning for freshwater ecosystems}

The development of freshwater conservation in South Africa mimics trends in the rest of the world, evolving from incidental inclusion of freshwaters as a result of terrestrial conservation action to the current acknowledgement of freshwater features as conservation priorities in their own right. In South Africa, early approaches to promote freshwater-specific conservation were based largely on identifying lists of sites that freshwater scientists knew were of conservation importance (Noble, 1974;
O’Keeffe, 1986). This approach was further advanced by developing scoring systems for comparing the relative importance of different sites (O’Keeffe et al., 1987; Boon, 2000). Scoring approaches used expert opinion and available data to rate sites according to a suite of attributes for diversity, naturalness, representativeness, rarity, species richness and special features. Problems exist with using scoring approaches to prioritise conservation action. Choosing high scoring sites over low scoring ones without explicitly considering how the sites complement or duplicate each other in their biodiversity content has a tendency to undermine representation, even if representativeness is a criterion that is scored and heavily weighted (Pressey and Nicholls, 1989). Duplication in biodiversity content of sites can also be counterproductive to making best use of limited resources. Systematic conservation planning addresses these problems through setting explicit conservation targets for representing biodiversity. The concept of complementarity is used to ensure achievement of these targets in an efficient manner (Margules and Pressey, 2000). Complementarity of a site is calculated as the contribution it makes to conservation targets not yet achieved in the existing set of conservation areas (Sarkar et al., 2006). This value is a relative measure that needs to be recalculated each time a new site is added to the conservation area network.

Key steps or stages that form part of a systematic conservation planning process are variously listed and described in literature by Margules and Pressey (2000), Knight et al. (2006a), Nel et al. (2009) and Pressey and Bottrill (2009). Some systematic conservation planning processes also couple spatial planning with steps that promote implementation of the planning products. These steps are dealt with in the following section on striving for implementation. In the remainder of this section we focus on 3 relatively generic steps in systematic conservation planning, dealing with incorporating representation, persistence and efficiency into spatial planning. We describe freshwater-specific national data from South Africa and draw primarily on examples from the FEPA project (Nel et al. 2011a), as it represents the most recent collation of national-level data for systematic conservation planning of freshwater ecosystems in South Africa. As with most systematic conservation planning exercises, limitations to the input data used by the FEPA project still exist. The need for improving these, through on-going research and monitoring investments, is discussed in detail in Nel et al. (2011b).

\section{Incorporating representation into spatial planning}

The need to represent examples of all biodiversity in a planning region stems from a realisation in the 1980s that protected areas were biased in the biodiversity they contained, mostly favouring sites with low economic potential (often mountainous areas) and ignoring those in highly productive areas (e.g. lowland biodiversity) (Margules and Pressey, 2000). Planning for representation requires identification of biodiversity features and the setting of targets, e.g. percentage of ecosystem type (Thieme et al., 2007) or number of species (Sowa et al., 2007), that are sufficient in extent to conserve a representative set of these features and allow them to persist or evolve naturally over time.

Because systematic conservation planning is an inherently spatial process, it is necessary to map the biodiversity features within the planning region. However, complete species lists, or even biologically-defined communities, are lacking for most ecosystems, and particularly so for aquatic biodiversity (Abell, 
2002). Freshwater conservation planning therefore relies heavily on the use of biodiversity surrogates. An important advance in the ability to apply systematic conservation planning approaches in freshwater settings was the development of surrogate measures for freshwater biodiversity at an ecosystem level (Linke et al., 2011), such as ecosystem types.

Ecosystem types, which classify rivers and wetlands into groups of ecosystems that share similar characteristics and expected biodiversity, have been classified in a variety of ways for systematic conservation planning. Ideally, classification is informed by both biological data (e.g. species distributions) and physical data (e.g. climate, slope, geology). This has been accomplished through the use of Generalised Dissimilarity Modelling (GDM), which derives these biodiversity surrogates by modelling species turnover along environmental gradients (Ferrier et al., 2007). Similar modelling processes have recently been used to classify rivers in New Zealand (Snelder et al., 2007; Leathwick et al., 2011). In data-poor areas, it may only be possible to use physical attributes to define ecosystem types. For example, geology, climate, topography and size of the system can be used to infer hydrological and geomorphological characteristics that influence river or wetland biota, such as flow variability, channel morphology, substratum and water quality (Higgins et al., 2005; Ausseil et al., 2007; Thieme et al., 2007).

In South Africa, the need to identify different freshwater ecosystem types, in order to compare information between rivers and wetlands and to allocate priority uses to different ecosystems, has long been recognised (Harrison, 1959; Noble and Hemens, 1978; O'Keefe et al., 1989). Early national efforts focused on rivers, defining relatively coarse regions within which rivers shared similar characteristics: Harrison (1959) mapped 12 hydrobiological regions according to aquatic biota and water chemistry; 6 regions were defined by Dallas et al. (1995) based on water chemistry; Eekhout et al. (1997) classified 10 biogeographic regions using cluster analysis of 645 species of riverine plants, fish and macro-invertebrates; quaternary catchments were classified according to hydrological flow variability (Hannart and Hughes, 2003); Kleynhans et al. (2005) devised a 2-level hierarchy of river ecoregions, based on climate, geology, vegetation and biological distributions; and Partridge et al. (2010) describe 34 geomorphic provinces and 12 sub-provinces within South Africa, Lesotho and Swaziland, based on statistically defined breakpoints in the longitudinal and valley cross-sectional profiles generated for mainstem rivers using a digital terrain model.

Advances in Geographic Information Systems (GIS), together with the increased availability of spatial data, permitted finer resolution classification of river and wetland ecosystem types for identifying FEPAs (Nel et al., 2011b). River ecosystem types were mapped by combining existing information on South Africa's Level I freshwater ecoregions (Kleynhans et al., 2005), flow variation (DLA-CDSM 2005-7) and longitudinal zonation (Rowntree and Wadeson, 1999; Moolman et al., 2002). Wetland ecosystem types were derived according to Level 4 of the National Wetland Classification System (SANBI, 2009) by combining the dominant vegetation type (Mucina and Rutherford, 2006) that served for providing the regional context, with the landscape setting of a wetland (Nel et al., 2011b). This enabled mapping the distribution of 223 river ecosystem types and 792 wetland ecosystem types across the country.

Systematic conservation plans based on multiple biodiversity surrogates are more likely to capture the full variety of biodiversity across the planning region (Rodrigues and Brooks, 2007). For this reason, in addition to representing ecosystem types for rivers and wetlands, criteria for identifying FEPAs included: representing threatened freshwater fish species; representing free-flowing rivers (river reaches $>50 \mathrm{~km}$ long without dams); representing wetland clusters (groups of wetlands embedded in a relatively natural landscape, which maintain ecological processes such as migration of frogs and insects between wetlands); and using the presence of threatened frog and waterbird species to guide the selection of wetland FEPAs (Nel et al., 2011b).

\section{Incorporating persistence into spatial planning}

Early systematic conservation planning focused on representing biodiversity in an efficient set of protected areas. By the late 1990s the scope had expanded to include planning for the persistence of biodiversity across entire landscapes, recognizing that many natural processes responsible for maintaining biodiversity will not persist if such processes are not explicitly incorporated into spatial designs (Balmford et al., 1998). The setting of conservation targets for ecosystem types and species should ideally address the amount required to ensure persistence (e.g. the extent of each ecosystem type, or the number and size of populations adequate to ensure its long-term persistence). In addition to conservation targets, Nel et al. (2011c) identify 4 other principles that can be applied to support the persistence of freshwater biodiversity: selecting ecosystems of high ecological integrity, incorporating connectivity, identifying the full suite of areas important to population persistence (e.g. breeding, migration and feeding areas), and incorporating spatial surrogates for specific natural processes that can be mapped (e.g. water supply areas). The first two principles, selecting ecosystems of high ecological integrity and incorporating connectivity, serve as generic surrogates of persistence. These surrogates cater for a range of dynamic natural processes that are key drivers of the structure and functioning of most freshwater ecosystems. The incorporation of at least these two principles is likely to enhance the persistence of biodiversity in a freshwater conservation plan.

Ecological integrity is a measure of the ability of an ecosystem to function within its natural range of variation and evolve naturally over time (Westra et al., 2000). Selecting ecosystems of high ecological integrity incorporates many local-scale biological processes (e.g. competition, predation), as well as the natural physical and chemical processes that support the structure and functioning of freshwater ecosystems. In South Africa, the concept of ecological integrity is well-established and incorporated into the River Health Programme assessment methods (Strydom et al., 2006) as well as the national Present Ecological State categories (Kleynhans, 2000), each of which provide measures of the degree of modification from a natural, reference condition. Both these datasets were used to inform the choice of river FEPAs (Nel et al., 2011b), by giving preference to rivers of high ecological integrity. Where ecological integrity data did not exist (e.g. for smaller tributaries or wetlands), the information was inferred using the extent of natural land cover around the freshwater ecosystem and within its subcatchment as an indicator of deviation from natural ecological integrity (Nel et al., 2011b). The use of natural land cover as an indicator of ecological integrity stems from freshwater research that shows that, where no other data exist, land cover can be used to infer information about the impact that human activities have on freshwater systems (Stein et al., 2002; Amis et al., 2007; Linke et al., 2007).

The inherent connectivity of most freshwater ecosystems 


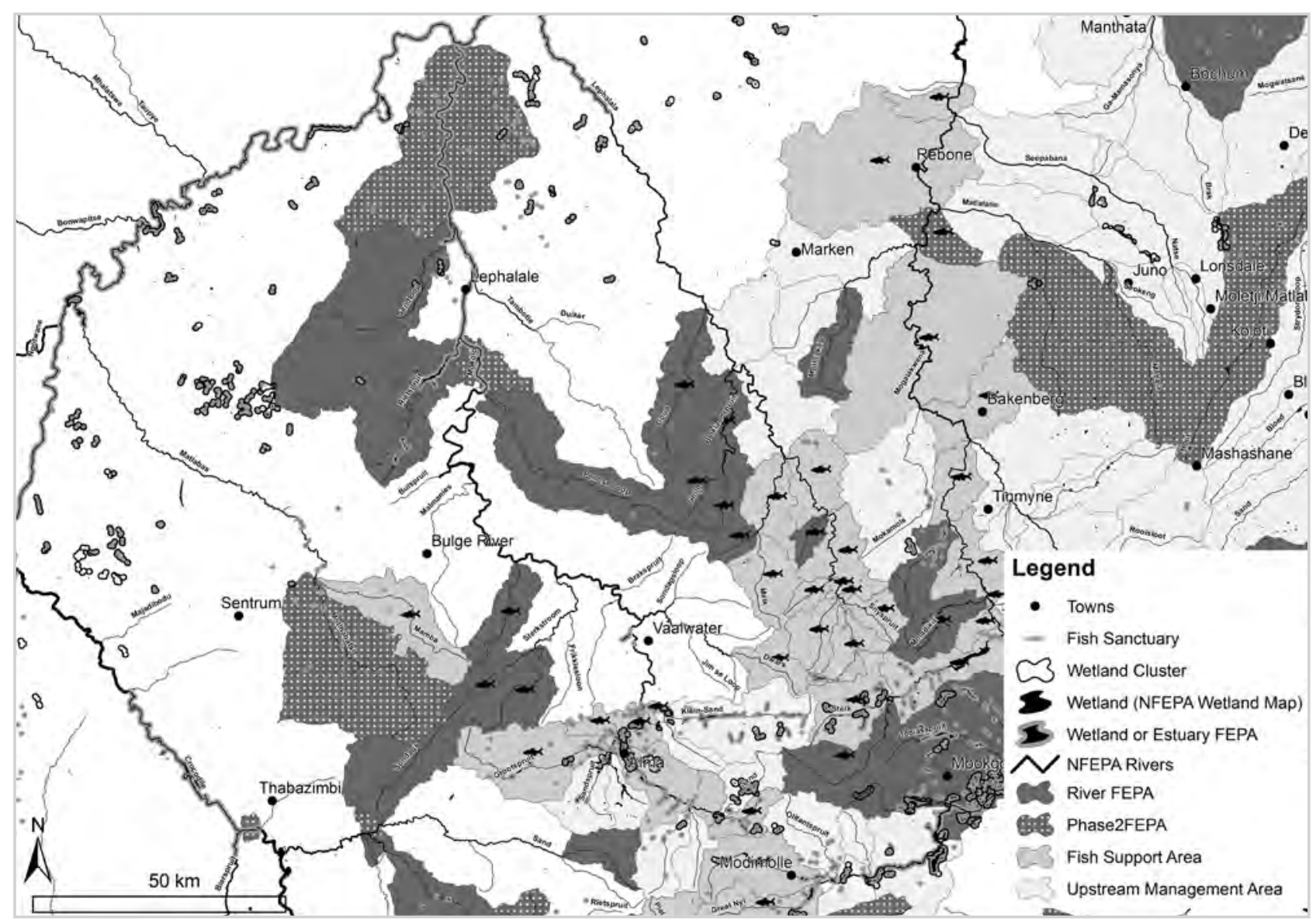

Figure 2

FEPA maps were developed for each of the 19 water management areas in South Africa. This map shows a section of the Limpopo Water Management Area to demonstrate the different management zones. For a detailed description of the categories on the FEPA map and their implications, consult Driver et al. (2011).

- along longitudinal, lateral and vertical dimensions (Pringle, 2001) - means that impacts upstream, downstream and from the surrounding catchment (lateral) need to be incorporated into freshwater conservation plans to support the persistence of the identified priority areas. Connectivity has been incorporated into freshwater conservation plans in several ways. To address lateral connectivity, most freshwater conservation plans use sub-catchments as planning units, identifying the surrounding catchment of each selected river reach and thus emphasizing the need to manage that river reach, as well as the surrounding land and the smaller network of streams flowing into the river reach. This concept has been applied in selecting river FEPAs in South Africa (Nel et al., 2011b). Sub-catchment planning units were identified around the river segments between the confluences of the1:500 000 river network GIS layer. These sub-catchments, roughly nested within South Africa's existing quaternary catchments (Midgely et al., 1994), and approximately a sixth of the size, were highlighted as the management unit for each stream selected as a river FEPA.

To address issues of longitudinal connectivity, freshwater conservation planners select connected river reaches to achieve representation. This can be done manually (Thieme et al., 2007 Sowa et al., 2007), or through the modification of conservation planning tools that build connectivity into complementaritybased algorithms by using GIS river network topologies (tree hierarchies) to assess candidate river reaches, relative to other upstream or downstream ones (Moilanen et al., 2008; Hermoso et al., 2012; Nel et al., 2011c; Rivers-Moore et al., 2011).

Because it is seldom feasible to place entire catchments under protection, the practicalities of connectivity are often dealt with through the allocation of multiple use zones, in which zones that contribute to representation of biodiversity are assigned stringent use restrictions, which decrease as one proceeds to zones that focus primarily on persistence of biodiversity (Abell et al., 2007). Longitudinal connectivity was incorporated into selecting river FEPAs in South Africa through ensuring that the conservation planning software, Marxan (Possingham et al., 2000), selected connected reaches for representation. This was achieved by applying a boundary penalty to non-headwater catchments, which encourages selection of connected subcatchments because they have fewer boundaries and thus lower penalties (Nel et al., 2011b). Sub-catchments selected for rivers were also assigned to different management zones on the FEPA maps (Fig. 2): river FEPAs are required to achieve conservation targets for river ecosystem types and threatened fish species and need to remain in a state of natural or near-natural ecological integrity, implying high use restrictions; Fish Support Areas need to be managed to support the threatened fish species or fish migration corridor functions that they were selected for, but this need not require as stringent use restrictions; and 
Upstream Management Areas indicate those catchments that need to be managed to ensure that water and land use does not impact on achieving the functions of downstream river FEPAs or Fish Support Areas.

\section{Incorporating efficiency into spatial planning}

The concept of complementarity was introduced in systematic conservation planning as a quantitative and transparent means of selecting sites that achieve conservation targets within a minimum number of sites (Sarkar et al., 2006). Sites are selected for conservation by selecting those that best contribute to conservation targets that have not yet been achieved. Once the site is added to the conservation area network, a new estimate of site contribution is calculated for the remaining unselected sites. This iterative process continues until all conservation targets are met.

To assist planners in this iterative process, numerous complementarity-based conservation planning tools have been developed (Sarkar et al., 2006). Initially, these tools focused only on complementarity, where conservation targets were achieved in the minimum amount of sites. Recognising that minimum sets did not necessarily translate to lower conservation costs (Naidoo et al., 2006), these were later augmented with algorithms that considered complementarity as well as the cost of conserving a site (Sarkar et al., 2006). In addition, conservation tools were developed with the ability to choose connected sets of sites, rather than sites that were scattered across the planning region. These tools were mostly developed for terrestrial and marine settings, but since 2007 various techniques have been applied to adapt these systematic conservation planning tools for use in freshwater conservation planning, through the ability to incorporate longitudinal connectivity (Linke et al., 2007; Moilanen et al., 2008) and, more recently, lateral connectivity (Hermosa et al., 2012).

\section{An implementation-enabling environment}

In the previous section we discussed 3 technical steps that influence the rigour of the planning process through which ecosystems are identified and prioritised. While improved planning methods and datasets can contribute to the technical quality and utility of a conservation plan, the value of such a plan is only realised through its effective implementation. To this end, conservation planners have pointed out that the availability of a substantial body of biodiversity information and a multitude of conservation plans have not resulted in much conservation action (e.g. Knight et al., 2008; Arlettaz et al., 2010). To promote bridging the so-called 'knowing-doing gap', some planners have proposed that planning processes be broadened in scope to integrate with social and institutional contexts (e.g., Pressey and Bottrill, 2009). Additional steps that are suggested include stakeholder engagement; understanding and mapping socio-economic dimensions; and interpreting the planning outcome for end users. We will now briefly explain each of these three potential additions to the planning process.

Firstly, the technical process of conservation planning, as outlined in the previous section, should be embedded within a stakeholder-driven implementation process (Margules and Pressey, 2000) to promote a sense of its ownership. Stakeholders include both the implementing agencies and key interest groups that may be affected by implementing the planning recommendations. In South Africa, the Department of Water Affairs and the Department of Environmental Affairs are key stakeholders, as they are the main authorities responsible for protecting freshwater ecosystems. The FEPA project team engaged agencies with conservation mandates at national, provincial and water management area level throughout the duration of the study (Driver et al., 2011). A key agency (SANBI) was part of the core project team from early conceptualisation. It was clear from this project that there is a strong relationship between the degree of agency engagement during the planning process and the subsequent uptake of the planning products. There seems to be a direct causal and reinforcing link between in-house agency expertise, ease and quality of engagement and adoption of the plan (see section below on absorptive capacity).

Secondly, the changing patterns of various social, economic and institutional variables will have an impact on the implementation of those plans (Knight et al., 2008). For example, landowner willingness to engage in conservation action can be essential to implementing the plan; therefore, mapping landowner willingness and using it to favour selection of priority sites for conservation may greatly enhance the ability to implement the planning outputs. To this end, some conservation planning exercises are expanding the list of expertise on their teams to include sociologists, anthropologists, policy specialists and economists. We contend that detailed mapping of socio-economics (e.g. willingness of landowners to engage and opportunity cost associated with land parcels) is more appropriate at the local-site scale, and are not convinced that it would add meaningful value to national-scale planning. As such, the FEPA project regarded data on ecological condition to be a sufficient surrogate for socio-economic and development pressures and patterns.

Thirdly, careful consideration should be given to packaging and disseminating conservation planning products (Knight et al., 2006b). Time and resources should be provided for this as part of the conservation planning exercise. Key policy mechanisms for implementing the conservation planning outputs should be identified in the initial phases of project design. Final map products should be interpreted according to these policy mechanisms, to facilitate their easy use by the key implementing agencies. Ideally, map products should also be accompanied by guidelines on how to use the maps within the different policy mechanisms. The FEPA project team worked closely with identified end users (for example relevant staff members from provincial government departments and catchment management agencies) to effectively engage with the policy and legal context in the water sector and biodiversity sector and to ensure that terminology used and map designs would speak to this receiving environment. For FEPAs, a range of different hard-copy, electronic and online dissemination tools were produced that were designed to feed into South African policy and legal tools for protecting freshwater ecosystems, including an atlas of map products (Nel et al., 2011a), a technical report for a scientific audience (Nel et al., 2011b), and an implementation manual that provided guidelines on how to apply the maps in the atlas in different policy and legal contexts (Driver et al., 2011).

Notwithstanding the potential of the above three steps to enrich conservation planning and increase the implementationfriendliness of resulting plans, we are of the view that most problems with slow uptake have less to do with the inadequacies in the planning process and more to do with the 'absorptive capacity' of the receiving environment. If we look beyond the planning project, what are the responsibilities of conservation scientists, conservation agencies and government towards 
creating an implementation-enabling institutional environment? In the remainder of this section we look forward at the challenge of securing the health of priority areas for freshwater conservation in South Africa (e.g. the recently-identified FEPAs), and particularly at what should happen outside of individual research or planning projects. We highlight a number of strengths and challenges and present these in the context of 4 inter-related and implementation-enabling conditions, namely, absorptive capacity, multi-domain cooperation, science extension, and adaptive management.

\section{Absorptive capacity}

A more detailed treatment of the role of 'absorptive capacity' in the context of public sector management and conservation of freshwater ecosystems is provided by Murray et al. (2011). To be able to effectively 'absorb' new information (such as that associated with a conservation plan), conservation agencies would need a critical level of in-house prior related knowledge. These agencies would also need individuals with the motivation and skills to build professional relationships and facilitate formal knowledge transfers and informal knowledge sharing, for example, between internal processes and external knowledge sources. To this end, Driver et al. (2011) suggest that all 9 of South Africa's provincial conservation authorities ideally each require at least 6 to 8 aquatic scientists and technicians, with expertise in limnology, hydrology, fish biology, aquatic invertebrate biology, aquatic plant biology and other aspects of aquatic ecology, in order to play an effective role in managing and conserving freshwater ecosystems. It is also essential to employ aquatic scientists in catchment management agencies, and district and local municipalities.

Within the science, management and policy domains related to freshwater conservation, human capacity in South Africa is vulnerable. Problems of an aging and eroding senior cadre of scientists and insufficient replenishment through new recruitment have been reported for some disciplines, for example, ichthyologists working in estuaries (Whitfield, 2011). We have experienced that the loss of one senior government official can derail a policy process and lead to substantial loss of momentum (Roux et al., 2008a). Yet, the biggest capacity challenge is probably at an implementation level, where none of the provincial implementation agencies has the full suite of aquatic and conservation expertise to enable them to effectively discharge their mandates regarding the management and protection of rivers, wetlands, and estuaries.

To address the capacity impasse , the South African National Biodiversity Institute (with assistance from the Lewis Foundation) has initiated a Biodiversity Human Capital Development Programme (BHCDP), which aims 'to contribute, over the next 20 years, to the growth of an equitable and skilled workforce of biodiversity professionals and technicians to optimally implement the sector's increasingly complex mandate' (SANBI, 2010 p. iv; see http://greenmatter.co.za. The BHCDP has, informed by a sector analysis, stakeholder consultations and research, produced a human capital development strategy for the biodiversity sector (SANBI, 2010). The strategy provides a framework for guiding organisations across the sector to develop internal human capital development strategies. The strategy follows a systemic approach, which provides mechanisms for connection, coordination and periodic evaluation across the sector, as well as sector-wide initiatives that have thus far been limited.

A systemic approach is indeed required, linking university postgraduate training, career-entry opportunities for appropriately knowledgeable and skilled people, and the nurturing and proper enablement of talented individuals in the workplace, whether in research or implementation. The latter include mentorship, exposure to interdisciplinary research projects and opportunities to travel to science meetings. For implementation agencies, guidance in terms of capacity requirements is provided in the form of a cross-sector policy recommendation (Roux et al., 2006), which states that each department or agency with an implementation mandate should plan and budget for the human capacity and financial resources to carry out such mandates; where human capacity implies both the skills (leadership, communication, integration) to facilitate cooperation among relevant groups as well as sufficient depth of knowledge in aquatic ecology and conservation science to absorb, co-produce and apply relevant new knowledge.

\section{Multi-party cooperation}

The development of a conservation plan typically draws on knowledge spanning several scientific disciplines, increasingly also from the social sciences. Implementation of such a plan also requires that we bridge the knowledge boundaries between research, policy and management functions, as well as facilitate cooperation across governance sectors such as water, agriculture, environment, conservation, mining, health and development. Regarding the facilitation of cross-sector cooperation, the regulation, management and conservation of freshwater ecosystems are dispersed amongst several government agencies in different sectors and at different levels of government (national, provincial and local). This situation gives rise to overlaps, gaps and inconsistencies in management and regulation frameworks, particularly since many of the agencies tend to operate independently within their areas of mandate. Without a concerted effort to achieve horizontal (across relevant sectors at each of the levels) coherence in intent and actions, as well as knowledge sharing amongst groups responsible for research, policy and management functions, the current downward trend in the state of freshwater ecosystems is likely to continue.

Multi-party cooperation as described above is not easy to achieve - it has costs, and the benefits are not necessarily explicit or immediate. The biggest cost is arguably in the form of time required from people with the ability to integrate new information with existing contextual information as well as to influence decisions in their home organisations. Such people, often senior staff members, are both scarce and typically overcommitted. Appropriately experienced and skilled facilitators are also required to enable conceptual integration and convergence of learning within a heterogeneous group (in terms of organisational affiliations, disciplinary backgrounds, vocabulary, policy contexts, social-ecological perceptions, and spatial and social jurisdictions) through identification with a shared goal (Hollaender et al., 2008). Once a proper understanding (not necessarily agreement) of one another's contexts and perspectives, trusting relationships and a common language exist, parties might be ready to suspend their own objectives in favour of contributing to a higher-level framework that is of mutual interest.

Substantial progress in cross-sector cooperation around freshwater ecosystem conservation has been made in South Africa in recent years - for example, in terms of national policy (Roux et al., 2008a), provincial implementation (Roux et al., 2011) and integrated water and land-use prioritisation (Nel et al., 2011a). These examples provide a platform to guide 
broad institutional commitment. Moreover, the South African National Biodiversity Institute (SANBI) has been a catalytic influence in developing a common vision and enabling environment for conservation action. To this end, SANBI has largely been responsible for establishing a coherent toolbox of legal mechanisms, and high levels of awareness and know-how about these mechanisms among relevant stakeholders at national and provincial levels of government - within the environmental sector and also the water sector. Mechanisms within this toolbox include the National Biodiversity Assessment, National Biodiversity Framework, National Protected Areas Expansion Strategy and the development of spatial biodiversity plans (known as bioregional plans, based on systematic conservation plans) in terms of the National Environmental Management: Biodiversity Act (No. 10 of 2004).

\section{Science extension}

Human norms and values are decisive factors in determining the enabling nature of an implementation environment. It is the underlying value system that ultimately determines the choices of people and the legitimacy of conservation (Balmford and Cowling, 2006; Van Houtan, 2006). Value-based trade-offs that are made at national and sub-national levels of governance determine the allocation of resources to perceived priorities, e.g. development, education, health, agriculture and conservation.

While science has become proficient at producing the biophysical and increasingly social and economic information to inform conservation decisions, it has traditionally stayed out of value debates. However, more and better information is unlikely to change the norms and values that influence the behaviour, choices and decisions of people. Rather, norms and values appear to evolve and spread like diseases, taking place through 'infectious transfers mediated by webs of contact and influence' (Ehrlich and Levin, 2005 p. 944). The media and commercial advertising probably exert more contact and influence on politicians and civil society than conservationists. To represent the virtues of freshwater conservation outside the scientific community, at least some conservation and aquatic scientists will have to become 'contagious agents' in the value debate. Such scientists would have to move beyond their conventional comfort zone 'into the complex normative world of laws, policies, and planning and become engaged in the purposive processes of decision making, behaviour change, and value transfer' (Reyers et al., 2010 p. 957). Even one 'superbug' could have a significant impact, as was demonstrated by aquatic scientist Peter Cullen, who interfaced with influential politicians and business people to establish a strategic water conversation in Australia (Lake et al., 2010).

The role of scientists in the development of conservation policy has attracted much interest in the past decade (for example, Robertson and Hull, 2001; Wallington and Moore, 2005). This relationship is often framed as a dichotomy between objective and value-free science and value-laden or even biased policy advocacy. We feel that at least some conservation scientists should aim to straddle the worlds of academia, policy formulation and operational implementation, and that the integrity of scientific information need not be compromised. To this end we strongly encourage even the most operationallyoriented scientists to subject their new findings and insights to the most rigorous peer review and to publish in high-quality journals. At the same time we feel that such publications do not signify completion of a project but instead provide a launch pad for wider communication and application of the findings. One necessary extension activity is simply to actively communicate research findings in new ways and to new audiences with the aim of influencing public discourse. The media can be a particularly powerful conduit to lay audiences and even the most tongue-tied scientists can apparently develop the skills to become a well-expressed media communicator (Baron, 2010). The second extension activity is for scientists to 'migrate' from research to practice, to work, for at least some period of time, in a real implementation context (e.g. Arlettaz et al., 2010). This could alleviate situations where there are no or insufficient numbers of agency scientists to ensure operational integration of conservation plans.

Scientists will likely experience a few challenges in their conversion to these extension activities. Firstly, because not all scientists might have the patience, skills-set and aptitude to participate in real-world institutional processes which are slow, messy and often irrational. Secondly, because engaging in time-consuming social processes is not very compatible with the academic reward system. The latter values the accumulation of publications in high-impact journals, student numbers and grant income. In return, small victories in the field are likely to encourage and give hope to conservation scientists who are otherwise confronted with rather depressing facts about habitat destruction and extinction rates (Swaisgood and Sheppard, 2010).

\section{Adaptive management}

Adaptive management is essentially about structuring our learning in situations where decisions might be contested and outcomes are not necessarily predefined. It is an approach and philosophy that enables action in the face of uncertainty; that is, to learn while we are doing in order to do better (Folke et al., 2005). Typical steps within an adaptive management approach include to:

- create a common vision in which stakeholders agree on the social, technical, economic, ecological and political contexts of the system to be managed;

- set objectives that may range from value-laden statements to scientifically credible and measurable endpoints;

- analyse various options for achieving the objectives that were derived in the previous step, predict their likely consequences, assess the acceptability of those consequences, and select a combination of management options that provide the best potential social-ecological system outcomes and learning opportunities;

- develop detailed action plans (including monitoring protocols) and allocate the necessary resources for implementing the options selected in the previous step; and

- reflect on progress in order to facilitate purposeful evaluation and learning (Roux and Foxcroft, 2011).

The importance of an adaptive approach to systematic conservation planning has been stressed in the literature. In several proposed planning processes the ideals of adaptive management are represented most notably in a final step for 'monitoring and evaluation' (Margules and Pressey, 2000; Salafsky et al., 2002; Groves, 2003; Knight et al., 2006a; Pressey and Bottrill, 2009). However, in practice there appears to be little evidence of an operational link between systematic conservation planning and adaptive management, with a recent search failing to identify a single documented example of a functioning systematic conservation system that fully integrates 
Figure 3

The general framework (from Roux et al., 2009) within which single-, double-, and triple-loop learning can be understood is as follows: An ultimate vision leads to a policy (design, assumptions, principles, etc.) to achieve it, which in turn requires a strategy (actions, activities, etc.) to implement, which leads to consequences from which learning takes place. In essence, single-loop learning changes what or how something is done. Doubleand triple-loop learning changes why things are done.

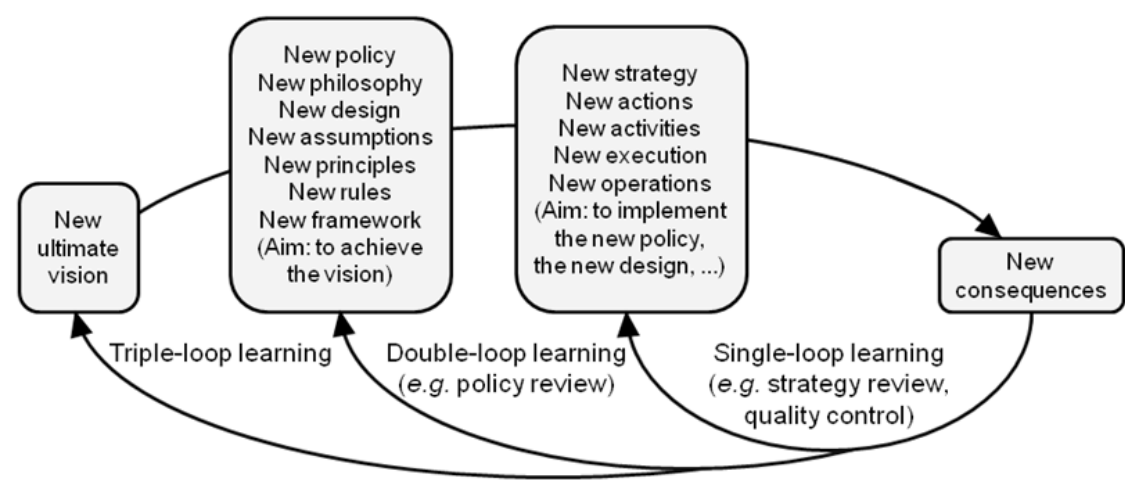

adaptive management principles (Holness and Biggs, 2011).

More generally, the implementation of adaptive management in natural resource management has also been met with difficulties (McLain and Lee, 1996; Walters, 1997; Rogers, 2003; Shea et al., 2002). Yet, significant progress has been made with an adaptive approach to the management of riverine ecosystems in multi-stakeholder contexts (e.g. McLoughlin et al., 2011; Pollard et al., 2011) as well as with the implementation of conservation objectives in general (see Roux and Foxcroft, 2011 - editorial to special issue on adaptive management in conservation).

We believe that, with appropriate and skilled facilitation and a relatively long-term commitment to it, an adaptive management approach is the most appropriate vehicle for turning the spatial and other recommendations from a systematic conservation planning exercise into operational reality. Of particular importance is implementing functional feedback loops to enable the trademark characteristics of adaptive management, namely, reflection, evaluation, learning and adaptation. These feedback loops are based on asking, and reflecting on, questions such as: is the monitoring programme appropriate; was the outcome acceptable; were the management options appropriate; and are the vision and objectives met (see Biggs et al., 2011)?

It is conceptually useful to appreciate that the feedback loops in adaptive management correspond to what are referred to as single-, double- and triple-loop learning (Fig. 3), where single-loop learning refers to learning concerned with skills, practices and actions (for example, resulting in changes such as would arise from routine quality control); double-loop learning facilitates the examination of those assumptions that drive our actions and behaviour patterns; and triple-loop learning allows for challenging and changing the values and norms that form the foundation of our governing assumptions (Argyris and Schön, 1996).

\section{Conclusion}

Each of the national freshwater conservation prioritisation studies of the 1970s, 1980s and 1990s broke new ground. Yet, advancement of this work over time seems to have been more from serendipity rather than from continuity of research strategy. The lack of institutional uptake of the associated products and an apparent inability to maintain the supporting research must have been disappointing for the relevant researchers. In comparison, it would appear that the focus on systematic conservation planning in the 2000s is characterised by relatively strong research momentum as well as explicit attention to institutional uptake and implementation of freshwater conservation plans. This has, at least in part, been possible because of the current supportive and enabling policy environment.

Freshwater conservation activities over the past decade span the development of basic methods, implementation strategies and policy objectives. These developments coalesced in the FEPA project and manifest as spatial priorities for freshwater conservation at the national scale. The implementationdriven FEPAs are directly applicable to various management tools within the biodiversity and water policy sectors in South Africa, such as integrated catchment management, water resource classification, listing of threatened river ecosystems, and the process of bioregional planning. As such, freshwater conservation planning has the potential to contribute significantly to sustainable and integrated water resource management in South Africa.

How do we convert potential benefit into real benefit? The experiences of the 1970s, 1980s and 1990s have shown how difficult it can be to maintain momentum for conservation plans. We suggest that efforts to develop scientifically-sound conservation plans should be complemented with at least equal attention to creating implementation-enabling institutional environments. Such a dual focus was an explicit aim during the development of FEPAs. Now that the project for identifying FEPAs has come to an end, a new phase of research is required. We believe that research for this new phase should be closely and iteratively linked to implementation activities. In such a research and implementation programme, researchers, funders and implementers/managers would accept joint accountability for articulating an aspirational goal and establishing a portfolio of inter-dependent projects aimed at moving South Africa closer to wise and sustainable governance of freshwater ecosystems.

Several universities, research organisations (e.g. CSIR), science facilities (e.g. South African Institute for Aquatic Biodiversity), conservation agencies (e.g. South African National Parks, Cape Nature, Ezemvelo KZN Wildlife), government regulators (e.g. Department of Water Affairs) and public entities responsible for policy, research and monitoring (e.g. South African National Biodiversity Institute) would have to be active partners in such a research programme. Furthermore, close cooperation between the research community, funding agencies (e.g. Water Research Commission and National Research Foundation) and operational implementers (e.g. catchment management agencies, provincial government departments and local municipalities) is desirable. We hope that this paper might provide some impetus for discussions on the creation of such a research and implementation programme for freshwater conservation in South Africa.

\section{Acknowledgements}


We would like to pay tribute to the Water Research Commission, the Departments of Water Affairs and Environmental Affairs, CSIR, the South African National Biodiversity Institute, and the National Research Foundation. Through their financial support, these organisations have enabled continuity in research efforts which resulted in the emergence of a new national scientific competence, namely systematic conservation planning for freshwater ecosystems. Amanda Driver and Amanda Pontier have provided valuable comments on an earlier draft of this paper. Chantal Petersen and Hlengiwe Mbatha are acknowledged for their effort in putting together the underlying data for Fig. 1, and Ashton Maherry is acknowledged for his production of Fig. 2. Two anonymous reviewers are thanked for their useful suggestions.

\section{References}

ABELL R (2002) Conservation biology for the biodiversity crisis: A freshwater follow-up. Conserv. Biol. 16 1435-1437.

ABELL R, ALLAN JD and LEHNER B (2007) Unlocking the potential of protected areas for freshwaters. Biol. Conserv. 134 48-63.

AMIS MA, ROUGET M, BALMFORD A, DAY J, NEL JL and KLEYNHANS CJ (2007) An assessment of the ecological integrity of freshwater ecosystems using land use surrogates. Water SA 33 215-222.

ARGYRIS C and SCHÖN DA (1996) Organizational Learning II. Theory, Method, and Practice. Addison-Wesley Publishing, Reading.

ARLETTAZ R, SCHAUB M, FOURNIER J, REICHLIN TS, SIERRO A, WATSON JEM and BRAUNISCH V (2010) From publications to public actions: When conservation biologists bridge the gap between research and implementation. BioScience 60 (10) 835-842.

AUSSEIL AE, DYMOND JR and SHEPERD JD (2007) Rapid mapping and prioritisation of wetland sites in the Manawatu-Wanganui region, New Zealand. Environ. Manage. 39 316-325.

BALMFORD A and COWLING RM (2006) Fusion or failure? The future of conservation biology. Conserv. Biol. 20 (3) 692-695.

BALMFORD A, MACE G and GINSBERG JR (1998) The challenges to conservation in a changing world: putting processes on the map. In: Mace G, Balmford A and Ginsberg JR (eds.) Conservation in a Changing World. Cambridge University Press, Cambridge, United Kingdom. 1-28.

BARON N (2010) Escape from the Ivory Tower: A Guide to Making Your Science Matter. Island Press, Washington DC.

BIGGS H, BREEN C, SLOTOW R, FREITAG S and HOCKINGS $M$ (2011) How assessment and reflection relate to more effective learning in adaptive management. Koedoe 53 (2) Art. \#1001. 13 pp.

BOON PJ (2000) The development of integrated methods for assessing river conservation value. Hydrobiologia 422/423 413-428.

DAILY GC (ed.) (1997) Nature’s Services: Societal Dependence on Natural Ecosystems. Island Press, Washington DC. 412 pp.

DALLAS HF, DAY JA and REYNOLDS EG (1995) The effects of water quality variables on riverine biotas. WRC Report No. 351/1/94. Water Research Commission, Pretoria, South Africa.

DLA-CDSM (2005-2007) 1:50 000 inland waterbodies and rivers. Department of Land Affairs, South Africa - Chief Directorate: Surveys and Mapping, Pretoria.

DRIVER A, MAZE K, ROUGET M, LOMBARD AT, NEL JL, TURPIE JK, COWLING RM, DESMET P, GOODMAN P, HARRIS J, JONAS Z, REYERS B, SINK K and STRAUSS T (2005) National spatial biodiversity assessment 2004: Priorities for biodiversity conservation in South Africa. Strelitzia 17 1-45.

DRIVER A, NEL JL, SNADDON K, MURRAY K, ROUX DJ, HILL L, SWARTZ ER, MANUEL J and FUNKE N (2011) Implementation Manual for Freshwater Ecosystem Priority Areas. WRC Report No. 1810/1/11. Water Research Commission, Pretoria.

DWAF (DEPARTMENT OF WATER AFFAIRS AND FORESTRY, SOUTH AFRICA) (2004) National Water Resource Strategy ( $1^{\text {st }}$ edn.). Department of Water Affairs and Forestry, Pretoria, South Africa. URL: http://www.dwaf.gov.za/Documents/Policies/NWRS/
Default.htm

EEKHOUT S, KING JM and WACKERNAGEL A (1997) Classification of South African rivers, Volume 1. Departmental of Environmental Affairs and Tourism, Pretoria, South Africa.

EHRLICH PR and LEVIN SA (2005) The evolution of norms. PLoS Biol. 3 (6) 943-948.

FERRIER S, MANION G, ELITH J and RICHARDSON K (2007) Using generalized dissimilarity modelling to analyse and predict patterns of beta diversity in regional biodiversity assessment. Diversity Distrib. 13 252-264.

FOLKE C, HAHN T, OLSSON P and NORBERG J (2005) Adaptive governance of social-ecological systems. Annu. Rev. Environ. Resour. 30 441-473.

GROVES CR (2003) Drafting a Conservation Blueprint: A Practitioner's Guide to Planning for Biodiversity. Island Press, Washington DC.

HANNART P and HUGHES DA (2003) A desktop model used to provide an initial estimate of the ecological instream flow requirements of rivers in South Africa. J. Hydrol. 270 167-181.

HARRISON AD (1959) General statement of South African hydrobiological regions. Report No. 1, Internal Report (Project 6.8H). National Institute for Water Research, Council for Scientific and Industrial Research, Pretoria, South Africa.

HERMOSO V, KENNARD MJ and LINKE S (2012) Integrating multidirectional connectivity requirements in systematic conservation planning for freshwater systems. Diversity Distrib. 18 (5) 448-458.

HIGGINS JV, BRYER MT, KHOURY ML and FITZHUGH TW (2005) A freshwater classification approach for biodiversity conservation planning. Conserv. Biol. 19 432-445.

HOLLAENDER K, LOIBL MC and WILTS A (2008) Management. In: Hirsch Hadorn G, Hoffmann-Riem H, Biber-Klemm S, Grossenbacher-Mansuy W, Joye D, Pohl C, Wiesmann U and Zemp E (eds.) Handbook of Transdisciplinary Research. Springer, Berlin. 385-397.

HOLNESS SD and BIGGS HC (2011) Systematic conservation planning and adaptive management. Koedoe 53 (2) Art. \#1029. 9 pp.

KLEYNHANS CJ (2000) Desktop Estimates of the Ecological Importance and Sensitivity Categories (EISC), Default Ecological Management Classes (DEMC), Present Ecological Status Categories (PESC), Present Attainable Ecological Management Classes (Present AEMC), and Best Attainable Ecological Management Class (Best AEMC) for Quaternary Catchments in South Africa. Institute for Water Quality Studies, Department of Water Affairs and Forestry, Pretoria.

KLEYNHANS CJ, THIRION C and MOOLMAN J (2005) A Level I Ecoregion classification system for South Africa, Lesotho and Swaziland. Resource Quality Services, Department of Water Affairs and Forestry, Pretoria.

KNIGHT AT, COWLING RM and CAMPBELL BM (2006a) An operational model for implementing conservation action. Conserv. Biol. 20 (2) 408-419.

KNIGHT AT, COWLING RM, ROUGET M, BALMFORD A, LOMBARD AT and CAMPBELL BM (2008) Knowing but not doing: selecting priority conservation areas and the researchimplementation gap. Conserv. Biol. 22 (3) 610-617.

KNIGHT AT, DRIVER A, COWLING RM, MAZE K, DESMET PG, LOMBARD AT, ROUGET M, BOTHA MA, BOSHOFF AF, CASTLEY GJ, GOODMAN PS, MACKINNON K, PIERCE SM, SIMS-CASTLEY R, STEWART WI and VON HASE A (2006b) Designing systematic conservation assessments that promote effective implementation: best practice from South Africa. Conserv. Biol. 20 (3) 739-750.

LAKE PS, LIKENS GE and RYDER DS (2010) Integrating science, policy and management of rivers: Peter Cullen's legacy. Mar. Freshwater Res. 61 733-735.

LEATHWICK JR, SNELDER T, CHADDERTON WL, ELITH J, JULIAN K and FERRIER S (2011) Use of generalised dissimilarity modelling to improve the biological discrimination of river and stream classifications. Freshwater Biol. 56 21-38.

LINKE S, PRESSEY RL, BAILEY RC and NORRIS RH (2007) Management options for river conservation planning: condition 
and conservation re-visited. Freshwater Biol. 52 918-938.

LINKE S, TURAK E and NEL JL (2011) Freshwater conservation planning: The case for systematic approaches. Freshwater Biol. $\mathbf{5 6}$ 6-20.

MARGULES CR and PRESSEY RL (2000) Systematic conservation planning. Nature 405 243-253.

McLAIN RJ and LEE RG (1996) Adaptive management: Promises and pitfalls. Environ. Manage. 20 (4) 437-448.

McLOUGHLIN CA, DEACON A, SITHOLE H and GYEDU-ABABIO $\mathrm{T}$ (2011) History, rationale, and lessons learned: Thresholds of potential concern in Kruger National Park river adaptive management. Koedoe 53 (2) Art. \#996. 27 pp.

MIDGLEY DC, PITMAN WV and MIDDLETON BJ (1994) Surface Water Resources of South Africa 1990: User’s Manual. WRC Report No. 298/1/94. Water Resource Commission, Pretoria.

MOILANEN A, LEATHWICK J and ELITH J (2008) A method for spatial freshwater conservation prioritization. Freshwater Biol. 53 577-592.

MOOLMAN J, KLEYNHANS CJ and THIRION C (2002) Channel Slopes in the Olifants, Crocodile and Sabie River Catchments. Internal Report No. N/0000/00REH/0102. Institute for Water Quality Studies, Department of Water Affairs and Forestry, Pretoria. $41 \mathrm{pp}$.

MUCINA L and RUTHERFORD MC (2006) The vegetation of South Africa, Lesotho and Swaziland. Strelitzia 19. South African National Biodiversity Institute, Pretoria.

MURRAY K, ROUX DJ, NEL JL, DRIVER A and FREIMUND W (2011) Absorptive capacity as a guiding concept for effective public sector management and conservation of freshwater ecosystems. Environ. Manage. 47 (5) 917-925.

NAIDOO R, BALMFORD A, FERRARO PJ, POLASKY S, RICKETTS TH and ROUGET M (2006) Integrating economic costs into conservation planning. Trends Ecol. Evol. 21 (12) 681-687.

NEL JL, DRIVER A, STRYDOM W, MAHERRY A, PETERSEN C, HILL L, ROUX DJ, NIENABER S, VAN DEVENTER H, SWARTZ E, and SMITH-ADAO LB (2011a) Atlas of Freshwater Ecosystem Priority Areas in South Africa: Maps to support sustainable development of water resources. WRC Report No. TT 500/11. Water Research Commission, Pretoria.

NEL JL, MURRAY KM, MAHERRY AM, PETERSEN CP, ROUX DJ, DRIVER A, HILL L, VAN DEVENTER H, FUNKE N, SWARTZ ER, SMITH-ADAO LB, MBONA N, DOWNSBOROUGH L and NIENABER S (2011b) Technical Report: National Freshwater Ecosystem Priority Areas project. WRC Report No. 1801/2/11. Water Research Commission, Pretoria.

NEL JL, REYERS B, ROUX DJ, IMPSON ND and COWLING RM (2011c) Designing a conservation area network that supports the representation and persistence of freshwater biodiversity. Freshwater Biol. 56 106-124.

NEL JL, ROUX DJ, COWLING RM, ABELL R, ASHTON PJ, HIGGINS JA, THIEME M and VIERS JC (2009) Progress and challenges in freshwater conservation planning. Aquat. Conserv.: Mar. Freshwater Ecosyst. 19 474-485.

NEL JL, ROUX DJ, MAREE G, KLEYNHANS CJ, MOOLMAN J, REYERS B, ROUGET M and COWLING RM (2007) Rivers in peril inside and outside protected areas: a systematic approach to conservation assessment of river ecosystems. Diversity Distrib. 13 341-352.

NOBLE RG (1974) An evaluation of the conservation status of aquatic biotopes. Koedoe 17 71-83.

NOBLE RG and HEMENS J (1978) Water Ecosystems in South Africa - A Review of Research Needs. South African National Scientific Programmes Report No. 34. Council for Scientific and Industrial Research, Pretoria. 160 pp.

O'KEEFFE JH (ed.) (1986) The conservation of South African rivers South African National Scientific Programmes Report No. 131. Foundation for Research Development (Council for Scientific and Industrial Research), Pretoria. $117 \mathrm{pp}$.

O'KEEFFE JH, DANILEWITZ DB and BRADSHAW JA (1987) An 'expert system' approach to the assessment of the conservation status of rivers. Biol. Conserv. 40 69-84.

O'KEEFFE JH, DAVIES BR, KING JM and SKELTON PH (1989) The conservation status of southern African rivers. In: Huntley BJ (ed.) Biotic Diversity in Southern Africa: Concepts and Conservation. Oxford University Press, Cape Town. 276-299.

PARTRIDGE TC, DOLLAR ESJ, MOOLMAN J and DOLLAR LH (2010) The geomorphic provinces of South Africa, Lesotho and Swaziland: A physiographic subdivision for earth and environmental scientists. Trans. R. Soc. S. Afr. 65 (1) 1-47.

POSSINGHAM HP, BALL IR and ANDELMAN S (2000) Mathematical methods for identifying representative reserve networks. In: Ferson S and Burgman M (eds.) Quantitative Methods for Conservation Biology. Springer-Verlag, New York. 291-305.

POLLARD S, DU TOIT D and BIGGS H (2011) River management under transformation: The emergence of strategic adaptive management of river systems in the Kruger National Park. Koedoe 53 (2) Art. \#1011. 14 pages.

PRESSEY RL and BOTTRILL MC (2009) Approaches to landscapeand seascape-scale conservation planning: convergence, contrasts and challenges. Oryx 43 (3) 464-475.

PRESSEY RL and NICHOLLS AO (1989) Efficiency in conservation planning: scoring versus iterative approaches. Biol. Conserv. $\mathbf{5 0}$ 199-218.

PRINGLE CM (2001) Hydrologic connectivity and the management of biological reserves: a global perspective. Ecol. Appl. 11 981-998.

REYERS B, ROUX DJ, COWLING RM, GINSBURG AE, NEL JL and O'FARRELL P (2010) Conservation planning as a transdisciplinary process. Conserv. Biol. 24 (4) 957-965.

RIVERS-MOORE NA, GOODMAN PS and NEL JL (2011) Scalebased freshwater conservation planning: Towards protecting freshwater biodiversity in KwaZulu-Natal, South Africa. Freshwater Biol. 56 125-141.

ROBERTSON DP and HULL RB (2001) Beyond biology: Towards a more public ecology for conservation. Conserv. Biol. 15 970-979.

RODRIGUES ASL and BROOKS TM (2007) Shortcuts for biodiversity conservation planning: the effectiveness of surrogates. Annu. Rev. Ecol. Evol. Syst. 38 713-737.

ROGERS K (2003) Adopting a heterogeneity paradigm: Implications for management of protected savannas. In: Du Toit JT, Rogers KH and Biggs HC (eds.) The Kruger Experience. Ecology and Management of Savanna Heterogeneity. Island Press, Washington DC. $41-58$.

ROUX DJ, ASHTON PJ, NEL JL and MACKAY HM (2008a) Improving cross-sector policy integration and cooperation in support of freshwater conservation. Conserv. Biol. 22 (6) 1382-1387.

ROUX DJ and FOXCROFT LC (2011) The development and application of strategic adaptive management within South African National Parks. Koedoe 53 (2) Art. \#1049. 5 pp.

ROUX DJ, MURRAY K, NEL JL, HILL L, ROUX H and DRIVER A (2011) From scorecard to social learning: A reflective co-assessment approach for promoting multi-agency cooperation in natural resource management. Ecol. Soc. 16 (1) 24. URL: http://www. ecologyandsociety.org/vol16/iss1/art24/.

ROUX DJ, MURRAY K and VAN WYK E (2009) Enabling Effective Learning in Catchment Management Agencies: A Philosophy and Strategy. WRC Report No TT 421/09. Water Research Commission, Pretoria. 67 pp.

ROUX DJ, NEL JL, ASHTON PJ, DEACON AR, DE MOOR FC, HARDWICK D, HILL L, KLEYNHANS CJ, MAREE GA, MOOLMAN J and SCHOLES RJ (2008b) Designing protected areas to conserve riverine biodiversity: Lessons from a hypothetical redesign of the Kruger National Park. Biol. Conserv. 141 (1) $100-117$.

ROUX DJ, NEL JL, MACKAY HM and ASHTON PJ (2006) CrossSector Policy Objectives for Conserving South Africa's Inland Water Biodiversity. WRC Report No. TT 276/06. Water Research Commission, Pretoria.

ROWNTREE KM and WADESON RA (1999) A Hierarchical Geomorphological Model for the Classification of Selected South African Rivers. WRC Report 497/1/99. Water Research Commission, Pretoria. 
SALAFSKY N, MARGOLUIS R, REDFORD KH and ROBINSON JG (2002) Improving the practice of conservation: a conceptual framework and research agenda for conservation science. Conserv. Biol. 16 (6) 1469-1479.

SANBI (2009) Further Development of a Proposed National Wetland Classification System for South Africa. Primary Project Report, September 2009. Prepared by the Freshwater Consulting Group (FCG) for the South African National Biodiversity Institute, SANBI, Pretoria.

SANBI (2010) A Human Capital Development Strategy for the Biodiversity Sector: 2010-2030. South African National Biodiversity Institute, Cape Town.

SARKAR S, PRESSEY RL, FAITH DP, MARGULES CR, FULLER T, STOMS DM, MOFFETT A, WILSON KA, WILLIAMS KJ, WILLIAMS PH and ANDELMAN S (2006) Biodiversity conservation planning tools: present status and challenges for the future. Annu. Rev. Environ. Resour. 31 123-159.

SCOTT JM, DAVIS F, CSUTI B, NOSS R, BUTTERFIELD B, GROVES C, ANDERSON H, CAICCO S, D'ERCHIA F, EDWARDS TC, ULLIMAN J and WRIGHT RG (1993) GAP analysis: A geographic approach to protection of biological diversity. Wildlife Monogr. 123 (January) 3-41.

SHEA K, POSSINGHAM HP, MURDOCH WW and ROUS R (2002) Active adaptive management in insect pest and weed control: Intervention with a plan for learning. Ecol. Appl. 12 (3) 927-936.

SHIKLOMANOV I (1993) World fresh water resources. In: Gleick PH (ed.) Water in Crisis: A Guide to the World's Fresh Water Resources. Oxford University Press, New York.

SKELTON PH, CAMBRAY JA, LOMBARD A and BENN GA (1995) Patterns of distribution and conservation status of freshwater fishes in South Africa. S. Afr. J. Zool. 30 (3) 71-81.

SNELDER TH, DEY KL and LEATHWICK JR (2007) A procedure for making optimal selection of input variables for multivariate environmental classifications. Conserv. Biol. 21 365-375.

SOWA SP, ANNIS G, MOREY ME and DIAMOND DD (2007) A
GAP analysis and comprehensive conservation strategy for riverine ecosystems of Missouri. Ecol. Monogr. 77 301-334.

STEIN JL, STEIN JA and NIX HA (2002) Spatial analysis of anthropogenic river disturbance at regional and continental scales: identifying the wild rivers of Australia. Landscape Urban Plann. $601-25$.

STRYDOM WF, HILL L and ELOFF E (2006) Achievements of the River Health Programme 1994 - 2004: A national perspective on the ecological health of selected South African rivers. Department of Water Affairs and Forestry, Pretoria.

SWAISGOOD RR and SHEPPARD JK (2010) The culture of conservation biologists: Show me the hope! BioScience 60 (8) 626-630.

THIEME M, LEHNER B, ABELL R, HAMILTON SK, KELLNDORFER J, POWELL G and RIVEROS J (2007) Freshwater conservation planning in data-poor areas: an example from a remote Amazonian basin (Madre de Dios River, Peru and Bolivia). Biol. Conserv. 135 484-501.

VAN HOUTAN KS (2006) Conservation as virtue: a scientific and social process for conservation ethics. Conserv. Biol. 20 (5) 1367-1372.

WALLINGTON TJ and MOORE SA (2005) Ecology, values, and objectivity: Advancing the debate. BioScience 55 (10) 873-878.

WALTERS C (1997) Challenges in adaptive management of riparian and coastal ecosystems. Conserv. Ecol. 1 (2) 1. URL: www. consecol.org/vol1/iss2/art1/.

WESTRA L, MIOLLER P, KARR JR, REES WE and ULANOWICZ RE (2000) Ecological integrity: integrating environmental conservation and health. In: Pimentel D, Westra L and Noss RF (eds.) Ecological Integrity and the Aims of the Global Integrity Project. Island Press, Washington DC. 19-44.

WHITFIELD AK (2011) A century of fish research in South African estuaries. Afr. J. Aquat. Sci. 35 (3) 211-225. 
http://dx.doi.org/10.4314/wsa.v39i1.15 Available on website http://www.wrc.org.za

ISSN 0378-4738 (Print) = Water SA Vol. 39 No. 1 January 2013 ISSN 1816-7950 (On-line) = Water SA Vol. 39 No. 1 January 2013 